\title{
Managing Fast-Track Construction Project in Qatar: Challenges and Opportunities
}

\author{
Temitope Egbelakin ${ }^{1}$, Olabode Emmanuel Ogunmakinde ${ }^{2, *(\mathbb{D}}$, Billie Teshich ${ }^{3}$ and Temitope Omotayo ${ }^{4}(\mathbb{D}$ \\ 1 School of Architecture and Built Environment, University of Newcastle, Callaghan, NSW 2308, Australia; \\ t.egbelakin@newcastle.edu.au \\ 2 Faculty of Society and Design, Bond University, Gold Coast, QLD 4229, Australia \\ 3 Al Asmakh Real Estate Development Company, Doha 122104, Qatar; b.teshich@massey.ac.nz \\ 4 School of Built Environment, Engineering and Computing, City Campus, Leeds Beckett University, \\ Leeds LS2 8AG, UK; t.s.omotayo@leedsbeckett.ac.uk \\ * Correspondence: bogunmak@bond.edu.au
}

Citation: Egbelakin, T.;

Ogunmakinde, O.E.; Teshich, B.;

Omotayo, T. Managing Fast-Track

Construction Project in Qatar:

Challenges and Opportunities.

Buildings 2021, 11, 640. https://

doi.org/10.3390/buildings11120640

Academic Editors: Agnieszka Leśniak and Krzysztof Zima

Received: 8 November 2021

Accepted: 6 December 2021

Published: 11 December 2021

Publisher's Note: MDPI stays neutral with regard to jurisdictional claims in published maps and institutional affiliations.

Copyright: (c) 2021 by the authors. Licensee MDPI, Basel, Switzerland. This article is an open access article distributed under the terms and conditions of the Creative Commons Attribution (CC BY) license (https:/ / creativecommons.org/licenses/by/ $4.0 /)$.

\begin{abstract}
Fast-track construction projects are becoming increasingly prevalent in the construction industry, particularly where completion time is essential. A high adoption rate in some of the Gulf Cooperation Council (GCC) countries and the lack of a conceptual understanding of the challenges inherent in such may jeopardize the future sustainability of the construction sector. To make an informed decision about adopting a fast-track construction method, it is necessary to first identify the opportunities and challenges associated with it. Therefore, this study examines the critical challenges impeding the performance of Qatar's fast-track construction projects. The research findings were analysed and triangulated using a real-life project as a case study and several data sources. The results of the research identified four critical categories of barriers: design and coordination-related, scope or change orders-related, material and equipment-related, and contractual-related barriers. In addition, strategies such as accurate information, constructability assessment, early involvement of operations and maintenance personnel, and the use of an effective change control system were identified for addressing the identified challenges. The findings are beneficial to professionals who are currently operating or planning to undertake construction projects in Qatar or other Gulf Cooperation Council (GCC) countries. This study recommends that project managers be more attentive to key barriers in order to improve the performance of fast-track projects and to meet clients' objectives.
\end{abstract}

Keywords: barriers; construction; fast-track; project management; Qatar

\section{Introduction}

Increased competition among multinational, private, and government organisations in the construction industry and property market has gradually encouraged clients and project managers to take strong actions to maintain profitability while ensuring high quality standards, commitments, and timely completion of projects [1]. Generally, project management processes encompass initiation, planning, execution, performance or monitoring, and closing [2]. While projects' completion time may vary depending on factors such as design, size, and funding, they can be fast-tracked. One way to achieve compressed project duration is via the fast-track construction delivery approach [3]. Fast-track construction, as suggested by Chen et al. [3], provides avenues to overcome the challenges of high construction costs and inflation currently plaguing the sector. The fast-track approach in construction and engineering sectors leverages the ability to effectively overlap and manage activities in the design, procurement, and construction activities concurrently in order to compress the expected project schedule [1]. In other words, the construction phase starts when the design is still at the conceptual phase. The growing acceptance and adoption of the fast-track project delivery approach by many clients in the construction sector is due to the high demand and competitive economic environment where modern 
business operates, providing pathways for rapid marketing of products or to the final point of consumption [4]. Although the fast-track project delivery approach has several benefits, such as accelerated project completion and reduced running costs, inadequate planning often causes delays, significant changes in scope, and, consequently, project cost overrun [5]. While project management processes may include phase management, planning, control, team management, communication, procurement, and integration, project phases are generally considered as initiation, planning, execution, monitoring and controlling, and closure. Effective project management of the processes and phases is very crucial to the successful management of project performance in order to meet clients' and stakeholders' objectives. Several challenges may arise while meeting the client's and the project's demands.

Compressing time schedule increases project complexity and creates more risks, which often occur as a result of overlap between the phases of project and the strategies adopted by the project teams to manage these risks [5]. Despite these challenges and increasing complexities associated with fast-tracking construction projects, there is an increasing adoption of this delivery approach in the Middle East countries [6]. For instance, in Qatar, where there is a need to meet the demands of increasing population growth while also providing essential infrastructure to host the FIFA World cup in 2022, the government is challenging the construction industry to deliver these projects using a fast-track method [7]. As of 2017, the trend of projects within the Qatar construction industry focuses on developing the nation's transport infrastructure (32\%) and creating modern residential and commercial facilities (51\%) as well as the hospitality environment, including leisure and entertainment $(17 \%)$ [7]. The fast-track approach was adopted in about $42 \%$ of these projects to increase the completion time [7]. The implications of using a fast-track approach include the prompt finalization of drawings and specifications, a smaller number of vendors, synergy of all areas of engineering, and just-in-time procurement. Among the several benefits of using the fast-track approach, construction time saving is critical. Despite this benefit, there is a lack of in-depth and conceptual understanding of the challenges inherent in this delivery, which may jeopardize the future sustainability of the construction sector.

Existing studies have identified several challenges that could hinder the success of fasttrack projects. For instance, Harthi [8] identified changes made by clients, consultants, and contractors, technology changes, safety consideration, shortage of skills and unavailability of equipment as barriers to fast-tracking a project. Other factors include risk liability of work overlooked, liability for design errors and omissions, lack of sufficient information, low contingency allowance, and rework and modifications [4,9-11]. A review of these studies revealed that the challenges are similar in most countries where the fast-track approach has been used, particularly in the Gulf Cooperation Council (GCC), and there are practical considerations for managing fast-track projects in a few settings. The GCC is made up of six wealthy countries (Bahrain, Kuwait, Oman, Qatar, Saudi Arabia, and the United Arab Emirates) that control the world's oil and have high GDP per capita. However, there is a gap in knowledge on the critical assessment of barriers to fast-tracked project management in the Gulf Cooperation Council (GCC) countries. It is vital to bridge this gap to enable better strategies to be formulated to overcome these barriers. This has become necessary in the GCC countries, where fast-tracked projects in the construction and engineering sector are becoming prevalent. Moreover, clients' characteristics (such as experience, value judgement, innovativeness, respect, proactiveness, and flexibility [12]), regulations, and construction practices vary from country to country and for specific projects. It is therefore essential that barriers to adoption are properly identified and conceptualized. The research reported in this paper explores the barriers impeding the successful management of a fast-track project in the construction sector and provides recommendations to overcome these barriers. The research findings will provide real-life contexts on issues surrounding fast-track project management in Qatar. Recommendations for the effective use of this delivery approach are made to ensure successful project performance and to meet the objectives of the client. 


\section{Literature Review}

\subsection{Fast-Track Project Approach}

Fast-tracking is often described as the overlapping and compressing of the different activities in the conceptual design, procurement, and construction phases in order to complete the project quickly and economically $[13,14]$. Fast-track project delivery differs from the other delivery models, such as the traditional approach where sequential design and construction is performed, i.e., completion of one stage leads to the commencement of another. Fast-tracking of projects has been around for some time. It is very similar to concurrent engineering $(\mathrm{CE})$ used in the manufacturing and engineering sector to accelerate production times $[11,15]$. In construction, several projects have been implemented using the principles of $\mathrm{CE}$ and are commonly known as accelerated construction or fast-track construction [16], which symbolizes the reduction of the specified schedule from design to handing over of the facility [15]. Park [17] argued that the design and build procurement approach could facilitate fast-track delivery of construction projects. Fast-track delivery could significantly reduce the project schedule [18] as well as reducing inflation and interest costs [19]. The fast-tracking approach allows project managers and other professionals to engage in conceptual design while simultaneously continuing to overlap project work packages and other activities [18]. According to Knecht [20,21], fast-track projects implemented via streamlining processes could lead to reduced schedule, consequently leading to reduced costs. Moreover, when construction project activities are carried out simultaneously, resources not required for a project can be deployed to another. This would reduce the project costs and improve organisational cash flow, payback period, and performance [22,23]. With the increasing client's demand and adoption of this fast-track delivery approach, construction and engineering organisations adopting this approach are considered to have a strategically competitive advantage over other competitors or emerging similar projects $[19,24,25]$.

Despite its various benefits, fast-track project delivery is subjected to complexities and risks when compared to other procurement methods, and is not without its shortcomings. Some of the implications of overlapping activities with inadequate scope definition include cost overrun, increased number of reworks, frequent change orders, and varying degree of contract issues $[10,21,26]$. Moreover, this delivery approach may not be compatible with the existing organisational standards and operating principles, especially if the organisation is not experienced with the use of this delivery approach [4]. According to [27], construction organisations operating in the competitive environments in the United Arab Emirates often adopt a fast-track delivery approach without proper planning and adjustments to their operating standards and policies, which could result in poor project performance. Although the fast-track method of project delivery has many advantages and limitations, it may not be appropriate for all projects. Several factors must be considered to assess each project's suitability for this delivery approach. These considerations include design suitability, aligning multistakeholder's and organisation's needs and engagement, previous experience of the contracting parties, scope implementation planning, forms of contract, risks assessment and management, safety reviews and regulatory compliance requirements, etc. $[3,8,10,18,25,27]$. Overall, it is important that project team members and stakeholders have a clear understanding, knowledge, and experience of the project in order to determine the viability of fast-tracking for a project. The following section discusses some of the factors affecting the delivery and management of fast-track projects.

\subsection{Factors Affecting Fast-Track Projects' Performance}

A number of factors affecting the management and performance of a fast-track projects have been documented in literature. One main factor relates to the extent to which the design activities overlap with the requirements of downstream construction activities. This may involve several risks, such as cost overruns, increased reworks, and poor quality control $[8,13,20]$. While fast-track projects could result in cost overruns, it has been argued in the literature that these costs can be offset by recurring inflation and interest costs, 
reduced land tax, and returns on investment returns via the use of the facility on time [20,21]. Another major factor relates to managing the scope changes in fast-track projects. Managing the extent of scope changes and rework may constitute an inherent risk to a fast-track project that is not adequately planned [9]. The fast-tracking is often driven by the desire to quickly complete the project within a short period of time. This approach is often characterized by the lack of adequate time for appropriate front-end planning, and inadequate scope definition during the conceptual and design phases when compared to other project delivery approaches [9]. The lack of adequate preplanning during the conceptual and design phases can lead to increased scope changes, which consequentially lead to inaccurate cost estimation, unexpected project delay, and quality management issues $[9,28]$. Moreover, increased changes and rework may lead to a number of nonvalued added activities on the project, thus leading to high wastage in the construction processes [29]. To reduce some of the impacts of increased scope changes, systematic change management systems must be installed from the onset of the project and agreed upon by all the project stakeholders and team members.

The form of contract and clauses adopted in fast-tack projects often affect the project delivery and performance. Forms of contracts are legal documents or mechanisms used to allocate project risks and liabilities between the parties to the contract, with the aim of aligning stakeholders' expectations with realities, complexities, and risks that are inherent in the project [10]. At the time of conducting this research in 2017, there are no published contractual frameworks or documents specific for implementing fast-track construction projects in literature. Risk allocation thus may not be allocated equitably among contracting parties $[10,15]$. Inequitable allocation of risks, ambiguous contract clauses, and the use of inappropriate contract form constitute the major source of contractual disputes between contracting parties in this type of project delivery method [30]. Often, the bone of contention in resolving these contractual disputes relates to the appropriate identification of the risk-bearer [10]. Possible outcomes of this unequal allocation of risks and liabilities relate to the use of higher percentages of contingencies and premiums by the project architects, engineers, and contractors in bid price, which could eventually lead to increased project costs, and, in some cases, expensive litigations [10,30]. According to the U.S. Federal Facilities Council's Report (Council and National Research Council, 2007), fast-track projects often have high numbers of claims when compared to other project delivery methods. Increased numbers of change orders for modifications and rework, as well as claim for delay damages, are common contractual challenges in fast-track projects [26]. Other sources of contractual disputes and liabilities associated with this form of project delivery approach include design errors and omissions, incorrect cost and schedule estimates, poorly implemented change orders, and reworks [10]. The mitigation of imperative contractual issues in a fast-track project, therefore, necessitates the development of contract strategies that would reduce the legal complications involved.

Furthermore, efficient resources such as material and equipment management could affect the productivity of fast-track projects [26]. Various factors, such as inaccurate drawings, transportation problems, continuous alteration of design and reworks, excess paperwork, and defective installation and products, could have negative impacts on material procurement and equipment management [31]. Poor material and equipment management that includes late procurement and delivery, poor warehousing, inventory, and vendor evaluation could result in project time delays, increased inventory and procurement costs, substandard quality, and loss of productivity $[19,26,32,33]$. Lastly, fast-track projects are often prone to several project risks. Managers of fast-tracked construction projects are sometimes challenged with decision-making to effectively reduce and manage associated risks by implementing a formal set of standards and guidelines for proactive risk management [26,34]. Appropriate risk management for fast-track projects can significantly reduce risks and challenges, while opportunities are being maximized [24]. Consequently, effective project management is thus crucial to the success of fast-track projects, as poor scheduling or timing can not only cause delays but also incur additional costs [35]. 
Summarily, the literature summarized above has identified the factors and barriers that could affect the management and delivery of fast-track projects within the construction sector. Fast-track projects are subjected to significant challenges related to project delivery and performance. However, few studies have attempted to analyse these barriers to successfully manage fast-tracked projects in the UAE, especially in Qatar. This study is particularly important to the state of Qatar due to the increasing prevalence of the adoption of the fast-tracking delivery approach and the urgent need to provide necessary infrastructure to host the FIFA World cup in 2022. As clients' characteristics, construction practices, and different regulations vary across different countries and particular projects, it is crucial to understand the barriers that obstruct the management of fast-track projects in Qatar and to explore ways to overcome the barriers. The results of the research are significant for the construction industry in Qatar to satisfy the demand of growing population, and to promote economic diversification, technological advancement, and growth.

\section{Materials and Research Method}

\subsection{Case Study Method}

This study uses the case study approach to explore barriers to the delivery and management of fast-track construction projects in Qatar. A real-life project was selected for the study because it enhances understanding of the issue in its natural settings [36] and allows direct participation of all stakeholders involved in the selected project. It also offers insights and explanations regarding the relationships between barriers affecting the management of fast-track projects. The three data collection approaches used in this study are evaluation of existing literature, content analysis of project documents, and online questionnaire. These methods are designed to ensure that data could be consistently collected, analysed, and verified. The purpose of using more than one data collection method was to ensure a converging line of evidence [37], thereby increasing the reliability of the findings. The review of existing literature was conducted to examine the current state of knowledge, which identifies factors that affect the management and performance of fast-track projects and to identify knowledge gaps. Insights from the review provided a pool of factors or constructs for relevance-validation in the context of the Qatar construction industry. The analysis of relevant documents and semi-structured interviews with project team members provided an in-depth and contextual understanding of the project background. It also aided in the identification and clarification of project challenges and opportunities for improvement. Likewise, the online questionnaire allowed the generalisation of the research findings and allowed a larger sample of project team members within a short period of time [38,39]. Details of the questionnaire administration and analysis are discussed in Section 3.3.

\subsection{Case Study Background}

The project under study is a multimillion-dollar fast-track project for an internal fit-out of a shopping plaza in Doha, Qatar. This project was selected due to its significance and fit with the research goal, as well as access to the project team and necessary research data. The shopping plaza comprises a three-level, $13,800 \mathrm{~m}^{2}$ retail and shopping area for a department store located in Doha's Katara Cultural Village. The $13,800 \mathrm{~m}^{2}$ space is designed for use of shops, cafes, restaurants, offices, spa, hotel, and landscaped parks. The main project management objective focuses on adequate coordination, management, and delivery of fully compliant works in accordance with the specified specifications and meets clients' objective of a safe and effective opening date. With an estimated budget of USD 11 million, the interior fit-out schedule, including the interior design, engineering services, procurements, and construction and installation packages, is expected to be completed in twenty-four months. The overall project time schedule was initially designed for twentyfour months for the design and construction phases. The design phase was expected to commence six months before the construction phase. However, it overlapped with the construction phase by three months. In reality, the project construction phase commenced 
thirteen months after it was scheduled and lasted for twenty-eight months, prolonging the completion date by $67 \%$. The project comprised geographically diverse teams made up of individuals whose languages, time zones, and work cultures vary. For instance, the main architectural designer is based in France, and the MEP design specialist is based in Singapore, while the main contractor and project management organisation are locally based. The FIDIC Red Book was adapted as a contract with the inclusion of specific project clauses as an addendum. The analysis of the project under study provides a detailed understanding of the real-life context of issues related to factors serving as obstacles to fast-track project management.

\subsection{Review of Existing Literature and Document Analysis of Project Documents}

A review of existing studies has shown that researchers have reported various factors that could act as barriers to project performance and objectives of fast-track projects [3,8-10,19,26,39-41]. In addition, content analysis of relevant project documents and information discussions using established analytical procedures outlined by Yin [42] was used to assess the relevance validation of the identified barriers to the selected project and Qatar's construction industry. These three data collection methods revealed a comprehensive list of twenty-seven barriers to managing fast-track projects, outlined in Table 1. These barriers have been identified in literature from different countries, industries/sectors, and project contexts. They provide insights into frequently encountered barriers to the fast-track delivery method and are used in the development of the online questionnaire discussed in the subsequent paragraph.

Table 1. Barriers impacting the success of fast-track projects.

\begin{tabular}{ccc}
\hline Code & Factors & References \\
\hline B1 & Design errors and omissions & {$[18,19]$} \\
B2 & Lack of sufficient information & {$[9,10,41]$} \\
B3 & Poor coordination between work packages & {$[3,9,13,19,26,40]$} \\
B4 & Lack of design freeze approach & {$[9]$} \\
B5 & Lack of design review process & {$[9,19,40]$} \\
B6 & Untimely award of work packages & {$[19,40]$} \\
B7 & Long shop drawings' approval process & {$[26]$} \\
B8 & Comprehension of schedule & {$[9]$} \\
B9 & Changes made by owner & {$[8,9,19,26]$} \\
B10 & Change made by consultants & {$[8,9,19,26]$} \\
B11 & Change made by contractor & {$[8,9,19,26]$} \\
B12 & Technology changes & {$[3,8,9,40]$} \\
B13 & Defective workmanship & {$[13]$} \\
B14 & Rework and modifications & {$[10]$} \\
B15 & Late issue and buy-in of change orders & {$[9,10,13]$} \\
B16 & Safety consideration & {$[8]$} \\
B17 & Substitution of materials or procedures & {$[8,9,19,26]$} \\
B18 & Unavailability of equipment & {$[8]$} \\
B19 & Shortage of skilled labour & {$[8,19]$} \\
B20 & Delay in procurement & {$[9,13,41]$} \\
B21 & Workmanship or material not following specifications & {$[13]$} \\
B22 & Liability for inaccurate cost estimate & {$[10]$} \\
B23 & Liability for design errors and omissions & {$[8,10,13,19]$} \\
B24 & Delay damages & {$[10]$} \\
B25 & Risk liability of work overlooked & {$[10]$} \\
B26 & Conflict between contract documents & {$[9]$} \\
B27 & Low contingency allowance & {$[9,10]$} \\
\hline & & \\
\hline
\end{tabular}

\subsection{Questionnaire Design, Administration, and Data Analysis}

The twenty-seven (27) barriers listed and summarized in Table 1 offered insight into the development of the questionnaire. The use of established factors in existing research allowed the research participants to respond appropriately [43]. The questionnaire was 
developed using a five-point Likert scale, which was pretested with seven construction professionals (four contractors, two consultants, and one quantity surveyor) in Doha, Qatar. The purpose was to ensure that the questions were properly paraphrased in an easily understandable manner and format for the respondents, which helped to validate the questionnaire construct. The questionnaire was used to gather information on the participants' profile, project, barriers, and opportunities to improve the performance and management of fast-track projects. The questionnaire was hosted on the survey monkey website for three months. The target population includes all professionals working on construction projects in Qatar. The sampling frame adopted comprised project team members involved in the selected project. A list of potential respondents was drawn from organisations (contractors and consultants) involved in the design and construction phases of the project. The list includes quantity surveyors, design architects, interior and fit-out designers, claim consultants, structural, mechanical and electrical engineers, and contractors performing different work items. Middle- to senior-level managers were purposely contacted as research respondents because of their strategic position to make decisions and influence the objectives and outcomes of the project. A total of seventy-eight professionals were contacted to participate in this study. In order to establish contact and explain the purpose of the study, e-mails were sent to the selected professionals. Of those who replied, follow-up emails were sent with an online link to the questionnaire. Ten of the sixty-two responses received had missing values of more than $15 \%$ and were considered incomplete. As recommended by Hair Jr et al. [44], responses with missing values more than $15 \%$ were excluded from the survey to ensure data reliability. Overall, in this study, fifty-two completed responses formed the basis for analysis.

With the aid of IBM SPSS v23.0, the data were cleaned, patterns matched, and barriers grouped using a number of statistical analyses. Kolmogorov-Smirnov normality test was carried out to determine the distribution of data and the goodness of fit of the dataset [44]. The results of the Kolmogorov-Smirnov test show that there is no significant difference $(p \geq 0.05)$ between most of the measuring items or barriers and the distribution. Similarly, the probability plot assessment supports the normal distribution of data and provides the rationale for the use of parametric statistical tests. To determine the reliability of the measurement scale and the internal consistency between the barriers used in the questionnaire, Cronbach's alpha $(\alpha)$ reliability test was conducted [45]. The Cronbach's coefficient $(\alpha)$ value of 0.821 indicated a reliable scale at $5 \%$ significant level and a high level of internal reliability of the identified barriers, which is consistent with Hair et al.'s [46] recommendation. The Relative Importance Index (RII) was used to determine key variables from the list of factors. Generally, RII is expressed in percentages and can be obtained using the formula in Equation (1). The RII for each factor was calculated to identify the critical barriers that project team members should be concerned about in the management of fast-track projects.

$$
\mathrm{RII}=\sum \frac{w}{A * N}
$$

$w=$ Weight for the rating scale ( 1 to 5 )

$A=$ Highest weight (5)

$N=$ Total number of responses

The Kendall coefficient test was conducted to check the level of agreements between the different respondent groups [47], with respect to the ranking of barriers. Factor analysis was used to group the identified barriers into related categories [48], while Harman's single-factor test was conducted to check the potential for common bias.

\section{Results and Discussion}

\subsection{Profiles of the Respondents}

The respondent characteristics are summarized in Table 2 . The majority of respondents are engineers (38\%), project and site managers $(27 \%)$, designers $(19 \%)$, and claim consultant/quantity surveyors $(16 \%)$. As expected, the participants' designation showed 
that the majority are senior managers (46\%), directors (23\%), and middle-level managers (31\%). Respondents' organisation comprises contracting (52\%) and consultants (48\%), which indicates that both groups are adequately represented in the study. The average years of respondents' experience is ten, with the maximum being sixteen and the minimum, four years. Approximately $57 \%$ of the respondents have been involved in projects worth over USD 50 million. These characteristics indicate that the respondents are suitable to provide reliable data on the objectives of the project examined in this paper. Therefore, their opinions are expected to add quality and reliability to the research findings.

Table 2. Respondent profiles.

\begin{tabular}{|c|c|c|}
\hline Category & Frequency & $\%$ \\
\hline & Profession & \\
\hline Architectural & 3 & 6 \\
\hline Interior fit-outs & 7 & 13 \\
\hline Electrical & 8 & 15 \\
\hline Structural & 3 & 6 \\
\hline Mechanical & 9 & 17 \\
\hline Quantity surveyor & 5 & 10 \\
\hline Claim consultants & 3 & 6 \\
\hline Project managers & 5 & 10 \\
\hline \multirow[t]{3}{*}{ Site managers } & 9 & 17 \\
\hline & 52 & 100 \\
\hline & Years of experien & \\
\hline $0-5$ years & 4 & 8 \\
\hline $5-10$ years & 9 & 17 \\
\hline 10-15 years & 10 & 19 \\
\hline 15-20 years & 13 & 25 \\
\hline \multirow[t]{3}{*}{$20+$ years } & 16 & 31 \\
\hline & 52 & 100 \\
\hline & Organisation & \\
\hline Main contractor & 10 & 19 \\
\hline Subcontractors & 17 & 33 \\
\hline \multirow[t]{3}{*}{ Consultants } & 25 & 48 \\
\hline & 52 & 100 \\
\hline & Designation & \\
\hline Directors & 12 & 23 \\
\hline Senior managers & 24 & 46 \\
\hline \multirow[t]{2}{*}{ Intermediate-level managers } & 16 & 31 \\
\hline & 52 & 100 \\
\hline
\end{tabular}

\subsection{Relative Importance Index (RII) Results}

The RII results were used to identify and rank key barriers impeding fast-track project performance in Qatar. The analysis of variance (ANOVA) test was performed to verify whether there are significant differences between the RII scores of the two respondent groups (consulting and contractor). The RII results of all respondents and the ANOVA test results are summarized in Table 3 . The RII results of the barriers in column three range from 0.568 to 0.892 . The average scores of the strength of the barriers range from 2.15 to 4.51 . Using the min-max normalisation, factors with a normalized value greater than 0.50 are considered critical barriers since the minimum value was 0.00 and the maximum value was 1.00 , as shown in column five of Table 3 . Therefore, twenty factors were considered to be critical barriers. Design error and omission $(B 1 ; \mathrm{RII}=0.892)$ was ranked as the most critical barrier affecting the performance of the fast-track project examined in this study. A high level of design errors is inevitable in fast-track projects due to the need to begin construction activities prior to completion of design drawings and specification. The second-ranked barrier relates to the lack of sufficient and detailed information $(B 2 ; \mathrm{RII}=0.852)$ provided by the client and the design team to the other project members. Insufficient information often leads to significant discrepancies in drawings, resulting in an increased number of 
reworks and modifications. Third place was poor coordination between work packages (B3; $\mathrm{RII}=0.824)$, followed by the lack of design freeze $(\mathrm{B} 4 ; \mathrm{RII}=0.814)$, and the lack of design review process (B5; RII $=0.804$ ). The top five ranked barriers are all related to activities in the design phase, which emphasizes the importance of providing adequate time for design, as well as appropriate planning and coordination for fast-track project management.

Table 3. RII ranking of barriers.

\begin{tabular}{ccccccc}
\hline Code & Mean & RII & Standard Deviation & Rank & Normalized Value & ANOVA \\
\hline B1 & 4.46 & 0.892 & 0.672 & 1 & 1.00 & 0.738 \\
B2 & 4.26 & 0.852 & 0.928 & 2 & 0.84 & 0.497 \\
B3 & 4.12 & 0.824 & 1.005 & 3 & 0.75 & 0.941 \\
B4 & 4.07 & 0.814 & 1.078 & 4 & 0.72 & 0.698 \\
B5 & 4.02 & 0.804 & 0.938 & 5 & 0.69 & 0.708 \\
B14 & 4.00 & 0.800 & 0.926 & 6 & 0.68 & 0.092 \\
B27 & 4.00 & 0.800 & 0.926 & 7 & 0.68 & 0.345 \\
B9 & 4.00 & 0.800 & 0.951 & 8 & 0.68 & 0.386 \\
B10 & 3.95 & 0.790 & 0.999 & 9 & 0.65 & 0.846 \\
B11 & 3.93 & 0.786 & 0.856 & 10 & 0.63 & 0.667 \\
B15 & 3.93 & 0.786 & 0.910 & 11 & 0.63 & 0.239 \\
B26 & 3.93 & 0.786 & 0.986 & 12 & 0.63 & 0.069 \\
B22 & 3.88 & 0.776 & 1.074 & 13 & 0.60 & 0.858 \\
B13 & 3.86 & 0.772 & 1.014 & 14 & 0.59 & 0.386 \\
B20 & 3.84 & 0.768 & 0.974 & 15 & 0.58 & 0.751 \\
B17 & 3.81 & 0.762 & 1.006 & 16 & 0.56 & 0.533 \\
B24 & 3.81 & 0.762 & 1.118 & 17 & 0.56 & 0.490 \\
B18 & 3.79 & 0.758 & 1.226 & 18 & 0.54 & $0.025 *$ \\
B23 & 3.74 & 0.748 & 1.049 & 19 & 0.51 & 0.392 \\
B19 & 3.74 & 0.748 & 1.049 & 20 & 0.51 & 0.991 \\
B25 & 3.60 & 0.720 & 1.094 & 21 & 0.42 & 0.871 \\
B6 & 3.58 & 0.716 & 1.220 & 22 & 0.41 & 0.218 \\
B21 & 3.47 & 0.694 & 1.386 & 23 & 0.34 & 0.579 \\
B12 & 3.42 & 0.684 & 1.096 & 24 & 0.31 & 0.861 \\
B16 & 3.42 & 0.684 & 1.118 & 25 & 0.31 & 0.536 \\
B8 & 2.93 & 0.586 & 1.211 & 26 & 0.00 & 0.00 \\
B7 & 2.84 & 0.568 & 1.018 & 27 & 0.00 & \\
\hline
\end{tabular}

Normalized value $\geq 0.50=$ critical barrier; ${ }^{*}$ ANOVA value $\leq 0.05$ is significant at $p=0.05$.

To examine the level of agreement between respondents on their rating of the relative importance of the identified barriers, the Kendall's $W$ test was conducted. The intention was to ascertain the degree of consistency in their responses, and their understanding of the importance of these barriers in relation to fast-tracked project delivery. The result of the Kendall's W value is 0.087 , at $p<0.001$, which indicates a significant level of agreement between the barriers reported by the two respondent groups. The results of the ANOVA test presented in Table 3, column seven, showed that twenty-five barriers are significant, i.e., their values are greater than 0.05 . The results suggest that there are no significant differences in the perceptions of the relative importance of these barriers among the two groups of respondents. Safety considerations (B16) and material workmanship (B21) are two barriers that differ between the two groups. These barriers (B16 and B21) are more related to the activities and practices of the contractor. The RII rankings of these two barriers by the contractors (B16: RII $=0.826$, Rank 7; B21: RII $=0.792$, Rank 13) were higher than that of the consulting firms (B16: RII $=0.714$, Rank 22; B21: RII $=0.672$, Rank 23). The difference in the RII results suggests that inadequate safety considerations and poorquality material workmanship adversely affect the contactor more than the consulting firms. These two barriers could result in increased site accidents, poor reputation, and loss of future opportunities. Overall, the RII in this study highlights key critical barriers that consultants and contractors' project managers should pay particular attention to when handling fast-track construction projects in Qatar. 


\subsection{Results of the Factor Analysis}

In an effort to categorize the twenty barriers (i.e., factors with values greater than 0.50) into a few core factors, the factor analysis was conducted. To assess the sampling adequacy and appropriateness of factor analysis method used in this study, Kaiser-MeyerOlkin (KMO) and Bartlett tests were conducted [49]. The result of $\mathrm{KMO}=0.751$ implies a relatively compact correlation between the barriers. Therefore, factors analysis would produce reliable and distinct groupings from the data. In addition, the results of the Bartlett's test of sphericity $(\chi 2=1651.83$, Df $=135, p \leq 0.001)$ suggest that the sample size is adequate. The use and validity of factor analysis in this study were confirmed by these results. Harman's single-factor test result reveals that only one factor accounts for $6.23 \%$ of the variance in the data sample. This indicates that the dataset is not subjected to common bias.

Table 4 summarizes the factor groupings after Varimax rotation using the principal component analysis in IBM SPSS 23.0. All twenty barriers yielded factor loading values greater than 0.50 and are thus considered significant in interpreting the key groupings [50]. Four key groupings were extracted with eigenvalues greater than 1 , which jointly explained $75.35 \%$ of the total variance. Factor loadings, eigenvalue, communalities, and Cronbach's alpha values surpassed the defined limit values, indicating a higher level of confidence in data reliability. As summarized in Table 4, the twenty barriers were clustered in four groups. Five variables (B1, B2, B3, B4, and B5) were included in Group 1, which is called "design and procurement-related barriers". Group 2 consists of six variables (B9, B15, B10, $\mathrm{B} 11, \mathrm{~B} 14$, and B13) and is labelled "Scope or change orders-related barriers". Group 3 is responsible for four variables (B19, B17, B18, and B20), which are called "material and equipment-related barriers". Group 4 comprised five variables (B22, B27, B23, B24, and B26) loaded and is labelled "contractual-related barriers". The relevance of these barriers to managing fast-track projects is addressed in Section 4.4.

Table 4. Results of factor analysis.

\begin{tabular}{|c|c|c|c|c|c|}
\hline \multirow[b]{2}{*}{ Code } & \multirow[b]{2}{*}{ Barriers } & \multicolumn{4}{|c|}{ Barrier Groups } \\
\hline & & 1 & 2 & & 4 \\
\hline \multicolumn{6}{|c|}{ Grouping 1: Design Coordination-Related Barriers } \\
\hline B1 & Errors and omissions in design & 0.857 & - & - & - \\
\hline B2 & Lack of sufficient information & 0.817 & - & - & - \\
\hline B3 & Poor coordination between work packages & 0.702 & - & - & - \\
\hline B4 & No design freeze & 0.612 & - & - & - \\
\hline B5 & Lack of design review process & 0.581 & - & - & - \\
\hline \multicolumn{6}{|c|}{ Group 2: Scope or Change Orders-Related Barriers } \\
\hline B9 & Changes made by owner & - & 0.879 & - & - \\
\hline B15 & Late issue and buy-in of change orders & - & 0.854 & & \\
\hline B10 & Changes made by consultants & - & 0.779 & - & - \\
\hline B11 & Changes made by contractor & - & 0.758 & - & - \\
\hline B14 & Rework and modifications & - & 0.721 & & \\
\hline $\mathrm{B} 13$ & Defective workmanship & - & 0.596 & - & - \\
\hline \multicolumn{6}{|c|}{ Group 3: Material and Equipment-Related Barriers } \\
\hline B19 & Shortage of skilled labour & - & - & 0.864 & \\
\hline $\mathrm{B} 17$ & Substitution of materials or procedures & - & - & 0.813 & - \\
\hline B18 & Unavailability of equipment & - & - & 0.780 & - \\
\hline $\mathrm{B} 20$ & Delay in procurement & - & - & 0.615 & - \\
\hline \multicolumn{6}{|c|}{ Group 4: Contractual-Related Barriers } \\
\hline B22 & Liability for inaccurate cost estimate & - & - & - & 0.774 \\
\hline B27 & Low contingency allowance & - & - & - & 0.712 \\
\hline B23 & Liability for design errors and omissions & - & - & - & 0.640 \\
\hline B24 & Delay damages & - & - & - & 0.612 \\
\hline \multirow[t]{4}{*}{ B26 } & Conflict between contract documents & - & - & - & 0.581 \\
\hline & Eigenvalue & 5.406 & 2.313 & 2.085 & 1.466 \\
\hline & Variance (\%) & 32.035 & 25.563 & 10.424 & 7.329 \\
\hline & Cumulative variance (\%) & 32.035 & 57.598 & 68.022 & 75.351 \\
\hline
\end{tabular}




\subsection{Discussion}

This section focuses on four categories of barriers identified from the factors analysis and highlights key factors within each group that affect project performance. The understanding of these barriers would help project managers and other construction professionals to develop strategies that could be used to control and manage them in order to achieve a higher level of project performance and success. The results of this study apply to a single case study project.

\subsubsection{Group 1-Design and Coordination-Related Barriers}

This group highlights the impacts of the design and coordination issues on project activities and reflects a total variance of $32.04 \%$ (see Table 4). The five barriers in this group are (i) errors and omissions in design, (ii) lack of sufficient information, (iii) poor coordination between work packages, (iv) no design freeze approach, and (v) a lack of design review process. In the project under study, the architect was employed to produce conceptual design and schematic drawings based on client's specified budget and schedule. The project design, specification, and construction phases started concurrently. As a result of the fast-track approach adopted in this project, many design flaws and omissions were reported, leading to shortcomings in the design drawings. Such deficiencies could be attributed to a variety of design modifications by the client, the architect, and the contractors, as well as insufficient information provided by the consultants and the need to start the construction phase early. According to Blacud et al. [51], the extent to which activities in the design and construction phases are overlapped is dependent on the availability of information and nature of exchange among the project teams. Due to the fast-track approach adopted, a number of activities in both phases commenced with incomplete and nonfinalized information. In addition, the willingness of the client not to freeze the design criteria throughout the project [1] complicated the coordination efforts, as the client could make constant changes to the design throughout the project phases.

Another critical impediment identified in this group relates to the poor planning and coordination of overlapped work packages. The fast-tracking method used in the project challenged the planning and coordination of all work items in the design phase. From the project management perspective, the performance of the design phase was assessed on metrics such as percentage of errors and omissions, deviations from specified schedule, and overall cost. The design phase output accounted for over $20 \%$ rise in the original overall design costs, which culminated in a four-month delay in the timeline. The coordination of design in the project was further complicated by the geographically dispersed project teams and the participation of many organisations involved in the supply chain. For instance, as stated in Section 3.1, the main architectural firm is in France. This dispersion caused delays in responses to information exchange, inconsistent procedures, lack of collegial social environment, and increased coordination costs. The lack of a design review significantly affected the construction phase, including unfinished plans and specifications, the omission of work items, and the delay in construction time. This finding is consistent with previous studies $[9,19,40]$, which identified inability to review the design as a barrier impeding construction project progress. A detailed review of the design would assist to identify possible design errors and omissions, problems with sourcing specialist equipment and materials, and reduce the number of reworks. Importantly, the review of design could ensue that the design reflects the client's requirement and resolves fundamental buildability issues.

\subsubsection{Group 2-Scope or Change Orders-Related Barriers}

This group explained the impacts of scope changes on the project performance. This group comprises six barriers and is responsible for $25.56 \%$ of the total variance. As summarized in Table 4, the six barriers are (i) changes made by owner, (ii) late issue and buy-in of change orders, (iii) changes made by consultant, (iii) changes made by contractor as a result of poorly-defined scope, (iv) a high percentage of rework and modifications, and 
(vi) defective workmanship. As expected in fast-track projects, scope changes are inherent and constitute a critical barrier to successful project management and performance. In this project, a high level of change order was recorded. Information discussion with project team members from both the contractors and consultants' team believed that the owner is the major source of change orders in this project. As a result, owners generated about $50 \%$ of changes in this project. This finding corroborates the research results of Harthi's [8] study on UAE construction projects. Moreover, the client's failure to freeze design led to multiple changes even during the construction and installation phase. A high number of change orders undermined the project's ability to meet its performance targets, resulting in increased project costs and schedule delays. Furthermore, the client's nonfreeze design approach adopted resulted in continual modifications throughout the conceptual design and construction phases. For example, the client's idea of achieving absolute design quality by incorporating Hellenic Roman architecture into Arabic building styles led to a significant amount of rework and defective workmanship.

A high number of changes were also made by both the main and subcontractors due to the incomplete or poorly defined scope. Work packages allocated to subcontractors were based on incomplete design, drawings, and specifications, as well as poorly estimated contract price. The large number of drawing revisions required after the award of the contract resulted from an incomplete design. In several contract packages, many drawings were revised, added, and deleted, creating additional human resource and coordination costs for contractors and the project management team, respectively. Overall, the higher percentage of change orders in this project affected bids' accuracy and led to an increase in low productivity during the design phase and the slippage schedule. Change orders observed in this project are quite similar to what is reported in the literature $[8,9,19,26]$.

\subsubsection{Group 3-Material and Equipment-Related Barriers}

This is a group of four critical barriers that explained $10.42 \%$ of the total variance (see Table 4). These barriers are (i) substitution of materials or procedures, (ii) unavailability of equipment, (iii) shortage of skilled labour, and (iv) delays in procurement. The main contractor in this project was yet to be recruited during the conceptual design phase. The lack of adequate information on the local operational capacities for materials and skilled labour required at the project site during the conceptual design phase contributed significantly to procurement-related challenges. Similarly, due to the specifications of the France-based architect and design team, the unique construction techniques predominantly used in the region also contributed to the procurement issues, especially material sourcing. The availability of such vital information from a local contractor during the design phase is critical. The locally sourced main contractor had knowledge of local materials and expertise in fit-out construction; however, as the contractor was not involved in the design phase, the knowledge and expertise of local materials and fit-out construction could not be used. Consequently, the lack of consideration for local operational capacity, in particular during the design phase, resulted in a number of changes in drawings and specifications as well as rework and delays.

A review of the purchase order records and the delivery of materials and equipment shows that there are substantial delays in the procurement process. The client's ambition to achieve a distinctive architectural design and style depends on the availability of suppliers of materials and equipment, including sufficient skilled labour. Planning and procurement of materials and equipment relies on the provision of prompt and relevant information from clients, designers, and a wide range of materials and equipment suppliers. The delivery of these specialized materials may be delayed by a lack of appropriate information, errors and omissions in design, and changes in design, drawings, and specifications. For cases where such materials and equipment are not available, project delays are inevitable. This is another critical barrier in the case under study, which contributed to a number of material and procedural substitutions. Although the issue may be unique to the project, procurement delays are quite common on construction projects, suggesting that this finding 
is consistent with several other studies $[9,13,41]$ that have reported the same problem. The client ordered rework because the materials failed to meet the specifications and objectives of the project. In addition, the unavailability and/or late ordering of specific equipment and materials hampered the performance of the project in terms of the availability of resources, the expense of sourcing specialized skills, and the duration of delays. Errors and omissions in design also culminated in the late ordering of long-lead equipment. More so, it is worth noting that the preplanning phase of the project did not involve suppliers of long-lead equipment and specialized materials. Therefore, accurate information on specialized materials and equipment with long-lead times should be identified at an early stage in a fast-track project to enable timely order placement. This would result in the availability of onsite installation items by the due date.

\subsubsection{Group 4-Contractual-Related Barriers}

A number of crucial flaws in the application of traditional contractual framework to fast-track projects were highlighted in this group. Five barriers were identified, which explains $7.3 \%$ of the total variance (see Table 4). These barriers are (i) liability for inaccurate cost estimates, (ii) low contingency allowance, (iii) liability for design omissions and errors, (iv) delay damages, and (v) conflict between contract documents. The project examined in this study adopted the FIDIC contract (Red Book) as the form of contract. For this project, specific exculpatory clauses and provisions were included as an addendum to the contract for the purpose of risk transfer and sharing. The lack of published contractual framework for the implementation of fast-track construction projects has resulted in several contractual liabilities and legal issues. The contract included specific and conventional contractual terms, made up of agreements and written clauses, explaining what the parties to the contract must do as well as risk sharing. Exculpatory clauses were used to transfer project risk to other parties as there are no provisions in contract forms for this type of project. The responsibility for errors and omissions in the design was a significant contractual issue in the project. Attaining a level of design reliability in the project was threatened by frequent changes, incomplete design, and specifications, and a high percentage of errors and omissions. The low level of design reliability during the design phase resulted in an erroneous cost estimate for the allocated work packages, which increased the final project cost by $30 \%$. Although the use of exculpatory clauses transferred the liabilities for design errors, unfinished drawings, and specifications and incorrect cost estimation to the client, the evaluation of the cost performance of the project negates the objective of fast-tracking in relation to the cost-savings from schedule compression.

The combination of early construction and fast operation does not guarantee design accuracy. Incomplete drawings and specifications contributed to a $35 \%$ increase in total project costs and inaccurate estimates. Likewise, the information and data used in the project estimation and bidding process were not accurate. As far as the contract is concerned, certain exculpatory provisions were used to pass on to the client the risk and liability of inaccurate cost estimation. To minimize liabilities, the main contractor and subcontractors did not consider uncontrollable damage-related factors. In most work packages, the high fixed maximum price was used to compensate for the costs incurred in attempting to correct design errors or to start afresh.

In this project, errors and omissions in design created risk liabilities for activities that were omitted. In addition, many important aspects of the design were not allocated, which created a vacuum of legal responsibilities that caused legal disputes between the parties to the contract. The inclusion of exculpatory provisions in the addendum, open communication, and good planning and control of change orders helped to minimize the contractual obligations. More so, the number of claims on this project increased due to various design alterations, change orders, and inability to comprehend schedules. The terms of the contract allowed the main contractor and subcontractors to claim damages for delay. Nonetheless, the excusable and inexcusable delays in the project can be differentiated through delay analysis procedure, as stated in the contract. The impact of claims on the 
project was investigated by reviewing claims' management and final settlement documents. Such claims are derived primarily from the client's representative (i.e., project management consultant) database. A total of 480 claims, including change orders and verbal directions, were recorded.

The high number of claims reported for this fast-track project confirms the results of the United States Federal Facilities Report [52], that a large number of claims are common to fast-track projects compared to the conservatively scheduled delivery approach. In addition, the small conditional funds included in the contract and budget provisions was insufficient to offset the costs incurred due to high percentage of change orders and claims. The appropriation methods of the contingency fund were not stated in the contract and were based on a defined risk analysis approach. Contingency allocation for fast-track projects should therefore be sufficiently robust to allow for uncertainties inherent in the delivery approach. The use of the fund should also be made through a defined methodological risk appropriation. Overall, these findings support those of Moazzami et al. [10], indicating that risks associated with fast-track projects can be reduced through contract alignment with its unique characteristics.

\section{Opportunities for Overcoming the Barriers}

Informal discussions and analysis of project documents reveal potential practices and strategies for overcoming identified barriers. To ensure that the design and planning stage is successful, the provision of appropriate and relevant information to project team members is critical. This would ensure that the scope of the project is well defined and that the owner's responsibilities, risks, and needs are clearly understood. Consequently, the margins of error, omission, and rework is reduced, and the design reliability is enhanced. Moreover, readily available and accurate information is important for the procurement team, and others along the supply chain are critical to ensure that the precise equipment and materials are available when needed. Furthermore, early participation of operations and maintenance personnel in the design review process may incorporate downstream experience and knowledge of cost-effective operation and maintenance into the design of the project. In the event that maintenance and operational concerns are ignored in the facility design, associated issues may lead to changes at start-up or commissioning. Addressing the constructability issue during the conceptual design phase is also critical to the success of fast-track construction projects. As the design, procurement, and construction stages overlapped significantly, early involvement of contractors and subcontractors can help to determine project constructability at a very early stage in the design process. It is important that the constructability assessment is carried out early in the planning phase, as it ensures cost-effective and efficient construction. The launch of a formal document and a change control process is essential for the progress of any fast-track construction project. The process would ensure that modifications to the directives issued to project team members are discussed, and feedback is recorded, handled in a timely manner, and preserved. This is crucial in terms of achieving a quick buy-in and acceptance throughout the change order process. There is need for clear channels of communication between the design team, the client, and other members of the project to ensure a seamless information exchange and decisions. Project team members and clients can take a proactive approach to reviewing and approving drawings sooner than expected and as stipulated in their contracts.

\section{Conclusions}

Adopting a fast-track project delivery approach has become popular in the construction sector and is presently being pressured to facilitate the successful delivery of this approach. Existing studies have shown the existence of knowledge gaps in the critical assessment of barriers to the management of fast-track projects in the Arab states of the Persian Gulf, especially in Qatar. These barriers also need to be addressed in a vital way to enable better strategies to be implemented to overcome such barriers. The findings reported in this study filled this gap by examining the critical barriers to managing and 
executing fast-track construction projects in Qatar through a case study. To achieve this objective, evidence from three data collection sources, including a literature review and examination of related project records, a discussion of information and an online questionnaire were triangulated. The research results showed that twenty barriers are critical to fast-track construction project management, with the top five linked to the design and coordination of overlapped activities. The five most critical barriers include (i) design errors and omissions, (ii) lack of sufficient and detailed information, (iii) poor coordination between work packages, (iv) lack of design freeze approach, and (v) lack of design review process. They emphasized the importance of providing adequate time for the design, appropriate planning, and coordination for managing fast-track projects. In addition, factor analysis was conducted to categorize these barriers. The results revealed four underlying grouped barriers, namely, design and coordination-related, scope or change orders-related, material and equipment-related, and contractual-related barriers. The findings also showed that the most prominent of the four groups were design and coordination-related barriers, suggesting the need for project managers and other team members to concentrate more on these barriers to meet project performance objectives. To facilitate the success of fast-track projects, research findings indicated a few techniques that could be applied to address the established barriers. These techniques include the provision of sufficient information, the flow of information, the evaluation of constructability, the early participation of operations and maintenance personnel, and the systematic report and change control system. Such suggested techniques, when implemented correctly, might improve the performance of fast-track construction projects.

This study is not without limitations. It should be noted that the crucial barriers found, and the solutions suggested in this study, were drawn from only one construction project in Qatar. The findings will benefit construction professionals working in Qatar and other UAE countries due to similarities in operational procedures and economy. These findings may also be useful for professionals working in other sectors or countries. However, the sector/market-specific and regional differences need to be taken into consideration before any of the strategies proposed in this study are applied. In addition, the assessment of the relative importance of barriers as rated by respondents may be subjective as a result of individual experiences and roles played in the project. Although the use of self-report retrospective data is common in construction research [53], respondents' responses may differ, which increases the problem of common variance. Harman's single-factor test was conducted to check the potential for common bias. The result extracted only one factor which accounts for $6.23 \%$ of the variance in the data sample, suggesting that common bias is not a problem in the dataset. Moreover, the Cronbach's coefficient $(\alpha)$ result reported in Section 3.3 indicated a reliable scale at 5\% significant level. Overall, the findings of this study provide relevant information on key obstacles to the performance of Qatar's fast-track projects, as well as recommendations for the mitigation of these barriers. Due to the obvious unique characteristics of projects and their locations, the findings of this study may not be generalizable to other projects in the GCC or the world. However, the results are beneficial and crucial to the success of construction, architecture, and engineering companies preparing to pursue projects in Qatar. It may also be added to the list of case studies from which construction professionals can choose when evaluating or comparing similar processes or cases.

Author Contributions: Conceptualization, T.E., B.T. and O.E.O.; methodology, T.E., B.T. and O.E.O.; software, T.E., O.E.O. and B.T.; formal analysis, O.E.O. and B.T.; investigation, T.E., O.E.O. and B.T.; resources, T.E. and T.O.; writing — original draft preparation, O.E.O. and B.T.; writing—review and editing, T.E. and T.O.; supervision, T.E. and T.O. All authors have read and agreed to the published version of the manuscript.

Funding: This research received no external funding.

Institutional Review Board Statement: Not applicable.

Informed Consent Statement: Informed consent was obtained from all subjects involved in the study. 
Data Availability Statement: The data presented in this study are available on request from the corresponding author.

Conflicts of Interest: The authors declare no conflict of interest.

\section{References}

1. Akintoye, A.; Goulding, J.; Zawdie, G. Construction Innovation and Process Improvement; Blackwell Publishing Ltd.: West Sussex, UK, 2012.

2. Snyder, C.S. A Guide to the Project Management Body of Knowledge: PMBOK $\left({ }^{\circledR}\right)$ Guide; Project Management Institute: Newton Square, PA, USA, 2014.

3. Chen, Z.; Li, H.; Wong, C.T. An Application of Bar-Code System for Reducing Construction Wastes. Autom. Constr. 2002, 11, 521-533. [CrossRef]

4. Smith, N.J.; Merna, T.; Jobling, P. Managing Risk in Construction Projects, 3rd ed.; John Wiley \& Sons: Nashville, TN, USA, 2014.

5. Aleshin, A. Risk Management of International Projects in Russia. Int. J. Proj. Manag. 2001, 19, 207-222. [CrossRef]

6. Mehran, D. Exploring the Adoption of BIM in the UAE Construction Industry for AEC Firms. Procedia Eng. 2016, 145, 1110-1118. [CrossRef]

7. Humphrey, S. Qatar Construction Market Outlook 2017-2030; Plateau Group Inc.: Crossville, TN, USA, 2017.

8. Harthi, B.A.A. Risk Management in Fast-Track Projects: A Study of UAE Construction Projects. Ph.D. Thesis, University of Wolverhampton, Wolverhampton, UK, 2015.

9. Deshpande, A.S. Best Practices for the Management of Design in Fast Track Industrial Projects. Ph.D. Thesis, University of Cincinnati, Cincinnati, OH, USA, 2009.

10. Moazzami, M.; Dehghan, R.; Ruwanpura, J. Contractual Risks in Fast-Track Projects. Procedia Eng. 2011, 14, 2552-2557. [CrossRef]

11. Kwakye, A.A. Construction Project Administration in Practice; Routledge: London, UK, 2016.

12. Kulatunga, K.; Kulatunga, U.; Amaratunga, D.; Haigh, R. Client's Championing Characteristics That Promote Construction Innovation. Constr. Innov. 2011, 11, 380-398. [CrossRef]

13. Cho, K.; Hyun, C.; Koo, K.; Hong, T. Partnering Process Model for Public-Sector Fast-Track Design-Build Projects in Korea. J Manag. Eng. 2009, 26, 19-29. [CrossRef]

14. Kasim, N.B.; Anumba, C.J.; Dainty, A.R.J. Improving Materials Management Practices on Fast-Track Construction Projects. In Proceedings of the 21st Annual ARCOM Conference, London, UK, 7-9 September 2005; Volume 2, pp. $793-802$.

15. Squires, W.R.; Murphy, M.J. The Impact of Fast Track Construction and Construction Management on Subcontractors. Law Contemp. Probs. 1983, 46, 55. [CrossRef]

16. Delves, A.; Drayton, R.; Sheehan, T. Faster Construction on Site by Selection of Methods and Materials; Construction Industry Research \& Information Association: London, UK, 2002.

17. Park, M. Dynamic Planning and Control Methodology for Large-Scale Concurrent Construction Projects. Ph.D. Thesis, Massachusetts Institute of Technology, Cambridge, MA, USA, 2001.

18. Peña-Mora, F.; Li, M. Dynamic Planning and Control Methodology for Design/Build Fast-Track Construction Projects. J. Constr. Eng. Manag. 2001, 127, 1-17. [CrossRef]

19. Fazio, P.; Moselhi, O.; Theberge, P.; Revay, S. Fast-Tracking of Construction Projects: A Case Study. Can. J. Civ. Eng. 1988, 15, 493-499. [CrossRef]

20. Knecht, B. Fast-Track Construction Becomes the Norm-Client, Architect, and Construction Manager Must Perform a Delicate Balancing Act to Shrink the Construction Process and Save Time and Money. Archit. Rec. 2002, 190, 123.

21. Knecht, B. Building Science \& Technology-Fast-Track Construction Becomes the Norm-Shrinking the Construction Process Requires a Delicate Balancing Act. Archit. Rec. 2002, 190, 123-132.

22. Curole, M.A. Mars Risk Management Program. In Proceedings of the Offshore Technology Conference, Houston, TX, USA, 5-8 May 1997.

23. Elvin, G. Integrated Practice in Architecture: Mastering Design-Build, Fast-Track, and Building Information Modeling; John Wiley \& Sons: Hoboken, NJ, USA, 2007.

24. Huovila, P.; Koskela, L.; Lautanala, M. Fast or Concurrent: The Art of Getting Construction Improved. Lean Constr. 1997, $143,159$.

25. Eastham, G. The Fast Track Manual: A Guide to Schedule Reduction for Clients and Contractors on Engineering and Construction Projects; European Construction Institute: Watford, UK, 2002.

26. Park, M. Dynamic Change Management for Fast-Tracking Construction Projects. In Proceedings of the 19th International Symposium on Automation and Robotics in Construction (ISARC), Maryland, USA, 1 September 2002; pp. 81-89.

27. Dainty, A.R.; Brooke, R.J. Towards Improved Construction Waste Minimisation: A Need for Improved Supply Chain Integration? Struct. Surv. 2004, 22, 20-29. [CrossRef]

28. Al-Dubaisi, A.H. Change Orders in Construction Projects in Saudi Arabia. Master's Thesis, King Fahd University of Petroleum and Minerals, Dhahran, Saudi Arabia, 2000.

29. Mbachu, J.I.; Egbelakin, T.; Rasheed, E.O.; Shahzad, W.M. Maximizing the Productivity of the Precast Concrete Plants by Implementing the Lean Management System. In Proceedings of the 5th Annual New Zealand Built Environment Research Symposium (NZBERS), Auckland, New Zealand, 17-18 October 2017; pp. 87-97. 
30. Mendis, D.; Hewage, K.N.; Wrzesniewski, J. Contractual Obligations Analysis for Construction Waste Management in Canada. J. Civ. Eng. Manag. 2015, 21, 866-880. [CrossRef]

31. Martin, J. Performance Measurement of Time and Cost Predictability. FIG Working Week 2003, 13-17 April 2003.

32. Bell, L.C.; Stukhart, G. Attributes of Materials Management Systems. J. Constr. Eng. Manag. 1986, 112, 14-21. [CrossRef]

33. Putra, C.C.W.; Ahmad, A.; Majid, M.A.; Kasim, N. Improving Material Scheduling for Construction Industry in Malaysia. In Malaysian Science \& Technology Congress; COSTAM: Kuala Lumpur, Malaysia, 1999; Volume 99, pp. 6-8.

34. Henry, R.M.; McCray, G.E.; Purvis, R.L.; Roberts, T.L. Exploiting Organizational Knowledge in Developing IS Project Cost and Schedule Estimates: An Empirical Study. Inf. Manag. 2007, 44, 598-612. [CrossRef]

35. Eppinger, S.D. Three Concurrent Engineering Problems in Product Development; MIT: Cambridge, MA, USA, 1995.

36. Crowe, S.; Cresswell, K.; Robertson, A.; Huby, G.; Avery, A.; Sheikh, A. The Case Study Approach. BMC Med. Res. Methodol. 2011, 11, 100. [CrossRef]

37. Creswell, J.W.; Plano Clark, V.L. Designing and Conducting Mixed Methods Research; SAGE Publications: Thousand Oaks, CA, USA, 2017.

38. Donut, M. What Is Quantitative Research? Available online: http:/ /www.marketingdonut.co.uk/marketing/market-research/ what-is-quantitative-research (accessed on 18 December 2016).

39. Kaplowitz, M.D.; Hadlock, T.D.; Levine, R. A Comparison of Web and Mail Survey Response Rates. Public Opin. Q. 2004, 68, 94-101. [CrossRef]

40. Kartam, N.A.; Al-Daihani, T.G.; Al-Bahar, J.F. Professional Project Management Practices in Kuwait: Issues, Difficulties and Recommendations. Int. J. Proj. Manag. 2000, 18, 281-296. [CrossRef]

41. Williams, G.V. Fast Track Pros and Cons: Considerations for Industrial Projects. J. Manag. Eng. 1995, 11, 24-32. [CrossRef]

42. Yin, R.K. Case Study Research and Applications: Design and Methods; Sage Publications: Thousand Oaks, CA, USA, 2017.

43. Rowlinson, S.M. An Analysis of Factors Affecting Project Performance in Industrial Buildings with Particular Reference to Design Build Contracts. Ph.D. Thesis, Brunel University School of Engineering and Design, Brunel University, London, UK, 1988.

44. Hair, J.; Sarstedt, M.; Ringle, C.M.; Gudergan, S.P. Advanced Issues in Partial Least Squares Structural Equation Modeling; SAGE Publications: Thousand Oaks, CA, USA, 2017.

45. Bonett, D.G.; Wright, T.A. Cronbach's Alpha Reliability: Interval Estimation, Hypothesis Testing, and Sample Size Planning. J. Organ. Behav. 2015, 36, 3-15. [CrossRef]

46. Hair, J.F.; Black, W.C.; Babin, B.J.; Anderson, R.E.; Tatham, R.L. Multivariate Data Analysis: Global Edition, 7th ed.; Pearson Education: Philadelphia, PA, USA, 2008.

47. Siegel, S.; Castellan, N.J. Nonparametric Statistics for the Behavioral Sciences; McGraw-Hill Book Company: New York, NY, USA, 1988.

48. Costello, A.B.; Osborne, J.W. Best Practices in Exploratory Factor Analysis: Four Recommendations for Getting the Most from Your Analysis. Pract. Assess Res. Eval. 2010, 10, 1-9.

49. Field, A. Discovering Statistics Using IBM SPSS Statistics, 5th ed.; SAGE Publications: London, UK, 2017.

50. Matsunaga, M. How to Factor-Analyze Your Data Right: Do's, Don'ts, and How-To's. Int. J. Psychol. Res. 2010, 3, 97-110. [CrossRef]

51. Blacud, N.A.; Bogus, S.M.; Diekmann, J.E.; Molenaar, K.R. Sensitivity of Construction Activities under Design Uncertainty. J. Constr. Eng. Manag. 2009, 135, 199-206. [CrossRef]

52. Council, F.F.; Council, N.R. Reducing Construction Costs: Uses of Best Dispute Resolution Practices by Project Owners; National Academies Press: Washington, DC, USA, 2007.

53. Podsakoff, P.M.; MacKenzie, S.B.; Podsakoff, N.P. Sources of Method Bias in Social Science Research and Recommendations on How to Control It. Annu. Rev. Psychol. 2012, 63, 539-569. [CrossRef] [PubMed] 